\title{
Design, Synthesis and Apoptosis Inducing Activity of Non-steroidal Flavone- methanesulfonate Derivatives on MCF-7 cell line as Potential Sulfatase Inhibitor
}

\section{Mahdiyeh HS Javadi}

Islamic Azad University Tehran North Branch

\section{Aida Iraji}

Shiraz University of Medical Sciences

maliheh safavi

Iran University of Science and Technology

Hamed Montazeri

Iran University of Medical Sciences

\section{Parastoo Tarighi}

Iran University of Medical Sciences

\section{Samane Eftekhari}

Iran University of Medical Sciences

\section{Lateifeh Navidpour}

Tehran University of Medical Sciences School of Pharmacy

Seyedeh Sara Mirfazli ( $\nabla$ saramirfazli@gmail.com )

Iran University of Medical Sciences https://orcid.org/0000-0001-7171-683X

\section{Research Article}

Keywords: Cancer, Breast cancer, Arylsulfatase, Steroid sulfatase, Flavone

Posted Date: April 29th, 2021

DOl: https://doi.org/10.21203/rs.3.rs-459998/v1

License: (c) (1) This work is licensed under a Creative Commons Attribution 4.0 International License.

Read Full License

Version of Record: A version of this preprint was published at Medicinal Chemistry Research on July 20th, 2021. See the published version at https://doi.org/10.1007/s00044-021-02767-w. 


\section{Abstract}

In recent years, focusing on new potent anticancer agents with selective activity is one of the greatest challenges in cancer therapy. Breast cancer is the most common cancer and the main cause of cancer deaths in women. The sulfatase enzyme plays an important role in converting the sulfated steroids into non-sulfate steroid hormones, which increases the growth and development of many hormone-dependent cancers, such as breast cancer. In this regard, structure-based optimization was conducted to design novel flavone-sulfonates pharmacophore as a new steroid sulfatase inhibitor. In the present work, the conventional methods for the synthesis of 4-oxo-2-phenyl-4H-chromen-7-yl methanesulfonate derivatives were reported. Their cytotoxicity was evaluated with MTT assay against a breast cancer cell line (MCF-7). The apoptosis inducing activity of the most cytotoxic compound $3 \mathrm{c}$ with an $\mathrm{IC}_{50}$ value of $0.615 \mu \mathrm{M}$ was evaluated in comparison to docetaxel in the presence of estradiol which is a crucial growth factor to survive the cancerous cells. The results of double staining Annexin V-FITC/PI analysis suggested that the cytotoxic activity of this compound $3 \mathrm{c}$ in MCF-7 cells occurs via apoptosis. Molecular docking studies were conducted to clarify the inhibition mode of the most promising compound (3c) over the sulfatase (1P49) binding site. The analysis revealed the role of hydrogen bond interaction with Gly181 and hydrophobic interactions through the 1P49 active site in the ligand-receptor complex as significant descriptors to rationalize the potential inhibition activity.

\section{Introduction}

Cancer is known as a chronic and non-communicable disease [1]. In more than a hundred different kinds of cancers, breast cancer is the most common cancer and the main cause of cancer deaths in women [2] The World Health Organization (WHO) reports biologically active hormones, including estrogens, as one of the most important factors to develop breast cancer. It was reported that the steroid levels, including estrone (E1), estradiol (E2), estrone sulfate (E1S), and estradiol sulfate (E2S), are enhanced in breast tumors compared to levels in the plasma and breast normal tissue [3]. The importance of estrogen production in the pathogenesis of breast carcinoma is supported by numerous studies $[4,5]$. Modern targeted cancer therapy has now focused on decreasing estrogen levels [6]

Sulfatase is widely distributed throughout the body, and it acts in physiological processes and pathological conditions [7]. Steroid sulfatase (STS) is known as a sulfatase enzyme that catalyzes the conversion of sulfated steroid (hormone precursors) to free steroid (active form) that stimulates the growth of tumors in various tissues especially the breast. STS has a mushroom-like shape, with two hydrophobic anti-parallel a-helices structures [8]. STS has been found in the membranes of the endoplasmic reticulum which anchoring the functional domain on the surface. The active site of STS is located deep in a cavity of the rounded part of the STS and rests near the membrane surface which forms four potential and two functional glycosylation sites [9]. The inhibition of STS is a novel therapeutic strategy for the treatment of estrogen-dependent tumors. Some STS inhibitors have entered clinical trials and their efficacy is under investigation in postmenopausal women with breast cancer [10, $11]$. 
Therefore, inhibition of this enzyme decreases the level of the active hormone, which responsible strategy to target the breast, endometrial, prostate, and other hormone-sensitive cancers [12].

\section{Results And Discussion \\ 2.1 The inhibitor design}

The STS inhibitors can be classified into four main categories; including steroid sulfamate based inhibitors, non-steroidal sulfamate inhibitors, steroid non-sulfamate based inhibitors and non-steroid nonsulfamate based inhibitors. The first steroidal STS inhibitors were designed based on the similarity with the substrate parental structure. Hallmark in this regard back to 1994 in which the replacement of OH of the sulfate group (A, Fig. 1) by an $\mathrm{NH}_{2}$, generated estrone-3-0-sulfamate known as EMATE (C, Fig. 1,) as an irreversible steroidal inhibitor. This compound performed a great activity in MCF-7 cells, with an $\mathrm{IC}_{50}$ value of $65 \mathrm{pM}$ [13]. The overall designing strategic was based on the substitution at the steroidal 3phenolic position with the resistance group to hydrolyze by the enzyme [14]. Therefore, the core aryl 0sulfamate pharmacophore was developed over the past few years [15]. Other steroidal inhibitors of STS containing different functional groups, for example, phosphonothioate (D), thiophosphate (E) and phosphate $(F)$ have been developed over time $[16,17]$. Unexpectedly, high estrogenicity was observed with estrogenic inhibitors and thus unsuitable effects were seen as anticancer agents. These results stimulate an intense search for orally active and non-estrogenic STS inhibitors [18].

The coumarin derivatives (containing two-ring coumarin aryl sulphamate) exhibits high activity against STS such as 4-methylcoumarin-7-0-sulfamate (G, COUMATE) with an $\mathrm{IC}_{50}$ value of $380 \mathrm{nM}$ against placental microsomes. Compound $\mathrm{H}$ demonstrated $71 \%$ STS inhibition in rat liver after $24 \mathrm{~h}$ single oral dose [19]. 667-COUMATE (I) as coumarin tricyclic derivatives showed an $\mathrm{IC}_{50}$ value of $8 \mathrm{nM}$ without significant estrogenic side effects. Also, compound $\mathrm{J}$ (Flavone-based agents) efficiently inhibited the purified human STS with $\mathrm{IC}_{50}=0.026 \mu \mathrm{M}$ and $\mathrm{K}_{\mathrm{i}}=0.19 \mu \mathrm{M}$ without estrogenic side effects in MCF-7 cells and good profile for the treatment of breast cancer $[20,21]$.

As a result, in this study, flavon structure as potent and irreversible STS inhibitors with time and concentration-dependent effects was selected as the backbone [22,23]. The sulphamate group attached to the aryl ring seems to blocks STS activity via providing nonbreaking bound. Besides the structural derivatization of target compounds mainly focused on the substitution on the methanesulfonate-flavone at the various position of the $B$ aryl ring.

\subsection{Synthesis of inhibitors}

Initially, for the synthesis of desired compounds, the benzoyl chloride derivatives (1a-i) were prepared, then reacted with 2,4-dihydroxyacetophenone, after baker-vankatarman rearrangement and neutralized with $\mathrm{HCl}$. The 7-hydroxy-2-phenyl-4Hchromen-4-one derivatives (2a-i) were synthesized in the presence of 
$\mathrm{K}_{2} \mathrm{CO}_{3}$ in acetone under reflux conditions for $8 \mathrm{~h}$. Finally, the reaction of $2 \mathrm{a}$-i with methane sulfonyl chloride in the presence of triethylamine gave the corresponding products $3 a-i$.

\subsection{Cytotoxic evaluation}

MCF-7 as a breast cancer cell line with the expression of STS were selected for further study. The $I_{50} S$ of all compounds are shown in table 2 comparing with docetaxel as a reference drug. The most active compound was $3 \mathrm{c}\left(\mathrm{R}=4-\mathrm{OCH}_{3}\right)$ with an $\mathrm{IC}_{50}$ value of $0.61 \mu \mathrm{M}$.

- The unsubstituted derivatives (3a) showed relatively good cytotoxicity with an $\mathrm{IC}_{50}$ value of $1.59 \mu \mathrm{M}$.

- The presence of one methoxy as a bulk-electron donating group led to an improvement in the cytotoxicity $\left(3 \mathrm{c}, \mathrm{IC}_{50}=0.61 \mu \mathrm{M}\right)$ comparing with the unsubstituted one. While the methyl moiety as small electron-donating without heteroatom getting compound $3 \mathrm{~b}\left(\mathrm{IC}_{50}=2.0 \mu \mathrm{M}\right)$ in which the cytotoxic potency significantly decreased.

- Similarly, the introduction of the electron-withdrawing group into 3a, resulting in $3 \mathrm{~d}(\mathrm{R}=$ para-Cl) and $3 e(\mathrm{R}=$ para-Br$)$ which led to increasing the cytotoxic activity compared to the unsubstituted derivative. However, the smaller group $(\mathrm{Cl})$ recorded better activity in comparison with $\mathrm{Br}$ counterparts.

- For the multi-substituted compound possessing $\mathrm{MeO}$, the reduction of anticancer activity was afforded for two substituted groups. The activity of these analogs changes are in the following order: 2,3-diOMe $\left(\mathrm{IC}_{50}=2.60 \mu \mathrm{M}\right)>2,4-\operatorname{diOMe}\left(\mathrm{IC}_{50}=3.21 \mu \mathrm{M}\right)>3,4-\operatorname{diOMe}\left(\mathrm{IC}_{50}=5.67 \mu \mathrm{M}\right)$.

- However, improvement in cytotoxicity was seen in compound 3i containing 2,3,4-triOMe with an $\mathrm{IC}_{50}$ value of $1.02 \mu \mathrm{M}$.

\subsection{Inhibition of STS in a cell-based assay}

Based on the results, compound $3 \mathrm{c}$ with the least $\mathrm{IC}_{50}$ value $\left(\mathrm{IC}_{50}=0.615 \pm 0.077 \mu \mathrm{M}\right)$ was selected to measure STS inhibitory activity. In this regard, proliferation assay was done for two concentrations of the selected compound alone and in the presence of $100 \mathrm{nM}$ estradiol. In these experiments, the well-known chemotherapy agent docetaxel (Doc) was used as the toxicity positive control. Based on data indicated in Fig. 2. The control group demonstrated around $100 \%$ of viability. As can be expected exposure to estradiol increases viability to more than $100 \%$ ( $p$-value $<0.05$ ). The results of the assay defined that the $3 \mathrm{c}$ was able to significantly decrease cell viability in two tested concentrations to around 58.2 and $68.3 \%$, respectively. Also, the group which was exposed to the co-treatment of $3 \mathrm{c}$ and estradiol indicated more cell viability in comparison with the $3 c$ confirming the decreased number of active steroids and the inhibition of STS. The cell viability in cell receives $500 \mathrm{nM}$ of docetaxel were significantly decreased compared to the control group. However, cells treated with Doc + estradiol showed approximately the same \% viability compare to cells exposed to Doc alone proposing the other mechanism of anticancer 
activity, not STS inhibition. In other words, estradiol treatment diminished the toxicity of $3 \mathrm{c}$ but not that of docetaxel in MCF-7 cells. This is based on the experiment in which, estradiol could compensate the $3 \mathrm{c}$ toxicity but not Doc toxicity. This could be explained by different inhibitory mechanisms of $3 \mathrm{c}$ and Doc in cell proliferation. Doc induced anticancer activity via effects by tubulin polymerization inhibition while $3 \mathrm{c}$ seems to work as an STS inhibitor.

\subsection{Cell apoptosis on MCF-7 cells}

Analysis of the flow cytometry double staining Annexin V-FITC/PI revealed that the synthetic compounds $3 \mathrm{c}$ reduced cell viability and induced apoptosis in human breast cancer cells. The flow cytometry analysis was used as a quantitative method of determining early and late apoptosis in treated cancer cells. Fig. 3. summarizes the data and showed an increase in the apoptotic index in MCF-7 cells treated with synthetic compound compared with negative control. The results of flow cytometric analysis showed that exposure of the MCF-7 cell line to the $\mathrm{IC}_{50}$ concentration of compound $3 \mathrm{c}$ induced early apoptosis in $16.3 \%$ of cells and late apoptosis in $10 \%$ of treated cells. According to Fig. 3., it was revealed that $13.5 \%$ of MCF-7 cells treated with positive control were at the early stage of apoptosis and $8.11 \%$ of the cells were at the late stage of apoptosis after $24 \mathrm{~h}$ treatment. The results confirmed that the cytotoxic activity of $3 \mathrm{c}$ breast cancer cells occurs via apoptosis.

\subsection{Docking study of STS}

Molecular docking was performed using smina in the Linux platform. The most potent ligand $3 \mathrm{c}$ was subjected to dock with the 3D structure of STS, 1P49. The interactions of the best-docked confirmation of $3 \mathrm{c}$ with the active site residues of STS are depicted in Fig. 4. The methanesulfonate group is well oriented near the entrance to the active site with conventional hydrogen bond interaction with Gly181 (distance: $2.61 \AA$ ) and two carbon-hydrogen bonds with Thr180 and Gly181. Pi-pi T-shaped interaction was also observed between the flavone backbone of $3 \mathrm{c}$ and the Phe178 residue (distance: $1.94 \AA$ ). The paramethoxy pendant was surrounded with several lipophilic amino acids and demonstrated two pi-alkyl interactions with Leu185 and Val186 as well as two carbon-hydrogen bonds with lle226 and Phe230 with $3.43 \AA$ and $3.06 \AA$ distance.

\section{Conclusion}

4-oxo-2-phenyl-4H-chromen-7-yl methanesulfonate derivatives were designed, synthesized, and evaluated for their inhibitory activity toward STS. This led to the identification of the most potent cytotoxic agent of the series, compound $\mathbf{3 c}$, with an $\mathrm{IC}_{50}$ value of $0.615 \mu \mathrm{M}$. Compound $\mathbf{3 c}$ showed a remarkable potency as anticancer agents on breast cancerous cell line (MCF-7) in the presence of estradiol via inhibiting cell proliferation through the proposed mechanism (blocking sulfatase enzyme). 3c significantly decreased the number of active estrogens by blocking STS, which can be counterbalanced by estradiol treatment. 
This mechanism is further authenticated by the lack of estradiol potential in decreasing Doc toxicity that exerts its effects by tubulin polymerization inhibition. The results of double staining Annexin V-FITC/PI analysis suggested that the cytotoxic activity of compound 3c in MCF-7 cells occurs via apoptosis. Molecular modeling studies showed compound $\mathbf{3 c}$ accommodated well in the STS active site via forming interaction with important residues.

\section{Material And Method}

\subsection{Synthesis of benzoyl chloride derivatives (1a-i)}

To the benzoic acid derivatives $(1 \mathrm{mmol})$, thionyl chloride $(4 \mathrm{mmol}, 0.28 \mathrm{~mL})$ was added dropwise at room temperature and the resulting mixture was heated under reflux for 2 hours. The extra thionyl chloride was evaporated under vacuum and benzene was added 3 times to remove the remaining of thionyl chloride.

\subsection{Synthesis of 7-hydroxy-2-phenyl-4H-chromen-4-one derivatives (2a-i)}

Initially, 2,4-dihydroxyacetophenone (152 $\mathrm{mg}, 1 \mathrm{mmol}$ ) and potassium carbonate (553 $\mathrm{mg}, 4 \mathrm{mmol}$ ) were dissolved in dry acetone. Then the appropriate benzoyl chloride derivative $(2 \mathrm{mmol})$ was added dropwise to the reflux solution for 5 minutes, and the resulting mixture was refluxed for 8 hours. After the completion of the reaction, the solvent was evaporated under vacuum. Next, $5 \mathrm{ml}$ of water and methanol (1:1) were added and the mixture was refluxed for 2 hours. The progression of the reaction was monitored by TLC. Then, the mixture was cooled to room temperature and was poured into ice and then neutralized with $5 \% \mathrm{HCl}$ solution. The precipitates were filtered and purified by preparative TLC (hexane: EtOAc, 1:1).

\section{7-Hydroxy-2-phenyl-4H-chromen-4-one (2a)}

White crystal, yield: $23 \%, \mathrm{mp}:>250^{\circ} \mathrm{C}, \mathrm{IR}\left(\mathrm{KBr}, \mathrm{cm}^{-1}\right): 3178(\mathrm{OH}), 1630 ;{ }^{1} \mathrm{H}$ NMR $\left(500 \mathrm{MHz}, \mathrm{DMSO}-d_{6}\right): \delta$ $10.81(\mathrm{~s}, 1 \mathrm{H}, \mathrm{OH}), 8.07\left(\mathrm{~d}, J=8.7 \mathrm{~Hz}, 2 \mathrm{H}, \mathrm{H}_{2^{\prime}, 6^{\prime}}\right), 7.89\left(\mathrm{~d}, J=8.7 \mathrm{~Hz}, 1 \mathrm{H}, \mathrm{H}_{5}\right), 7.55-7.62\left(\mathrm{~m}, 3 \mathrm{H}, \mathrm{H}_{3^{\prime}, 4^{\prime}, 5^{\prime}}\right), 7.01(\mathrm{~d}$, $\left.J=2.1 \mathrm{~Hz}, 1 \mathrm{H}, \mathrm{H}_{8}\right), 6.93\left(\mathrm{dd}, J=8.7,2.1 \mathrm{~Hz}, 1 \mathrm{H}, \mathrm{H}_{6}\right), 6.91\left(\mathrm{~s}, 1 \mathrm{H}, \mathrm{H}_{3}\right.$. Anal. calcd. for $\mathrm{C}_{15} \mathrm{H}_{10} \mathrm{O}_{3}: \mathrm{C}, 76.62 ; \mathrm{H}$, 4.23; O, 20.15. Found: C, 75.98; $\mathrm{H}, 4.54 ; 0,20.01$.

\section{7-Hydroxy-2-(4-methylphenyl)-4H-chromen-4-one (2b)}

White crystal, yield: $21 \%, \mathrm{mp}:>250^{\circ} \mathrm{C}$, IR $\left(\mathrm{KBr}, \mathrm{cm}^{-1}\right): 3069(\mathrm{OH}), 1628 ;{ }^{1} \mathrm{H}$ NMR $\left(500 \mathrm{MHz}, \mathrm{DMSO}-d_{6}\right): \delta$ $10.78(\mathrm{~s}, 1 \mathrm{H}, \mathrm{OH}), 7.96\left(\mathrm{~d}, J=8.7 \mathrm{~Hz}, 2 \mathrm{H}, \mathrm{H}_{2^{\prime}, 6^{\prime}}\right), 7.88\left(\mathrm{~d}, J=8.7 \mathrm{~Hz}, 1 \mathrm{H}, \mathrm{H}_{5}\right), 7.38\left(\mathrm{~d}, J=8.7 \mathrm{~Hz}, 2 \mathrm{H}, \mathrm{H}_{3^{\prime}, 5^{\prime}}\right), 7.0$ 
(d, J=2.1 Hz, 1H, $\left.\mathrm{H}_{8}\right), 6.92\left(\mathrm{dd}, J=8.7,2.1 \mathrm{~Hz}, 1 \mathrm{H}, \mathrm{H}_{6}\right), 6.85\left(\mathrm{~s}, 1 \mathrm{H}, \mathrm{H}_{3}\right), 2.36\left(\mathrm{~s}, 3 \mathrm{H}, \mathrm{CH}_{3}\right)$. Anal. calcd. for $\mathrm{C}_{16} \mathrm{H}_{12} \mathrm{O}_{3}$ : C, 76.18; $\mathrm{H}, 4.79 ; 0,19.03$. Found: $\mathrm{C}, 76.33 ; \mathrm{H}, 4.52 ; \mathrm{O}, 18.79$.

\section{7-Hydroxy-2-(4-methoxyphenyl)-4H-chromen-4-one (2c)}

White crystal, yield: $32 \%, \mathrm{mp}:>250^{\circ} \mathrm{C}$, IR $\left(\mathrm{KBr}, \mathrm{cm}^{-1}\right): 2981(\mathrm{OH}), 1685 ;{ }^{1} \mathrm{H}$ NMR $\left(500 \mathrm{MHz}\right.$, DMSO- $\left.d_{6}\right): \delta$ $10.93(\mathrm{~s}, 1 \mathrm{H}, \mathrm{OH}), 8.03\left(\mathrm{~d}, J=8.7 \mathrm{~Hz}, 2 \mathrm{H}, \mathrm{H}_{2,}^{\prime} 6^{\prime}\right), 7.87\left(\mathrm{~d}, J=8.7 \mathrm{~Hz}, 1 \mathrm{H}, \mathrm{H}_{5}\right), 7.11\left(\mathrm{~d}, J=8.7 \mathrm{~Hz}, 2 \mathrm{H}_{1} \mathrm{H}_{3^{\prime}, 5^{\prime}}\right), 7.0$ (d, J=2.1 Hz, $\left.1 \mathrm{H}, \mathrm{H}_{8}\right), 6.92\left(\mathrm{dd}, J=8.7,2.1 \mathrm{~Hz}, 1 \mathrm{H}, \mathrm{H}_{6}\right), 6.80\left(\mathrm{~s}, 1 \mathrm{H}, \mathrm{H}_{3}\right), 3.86\left(\mathrm{~s}, 3 \mathrm{H}, \mathrm{OCH}_{3}\right)$. Anal. calcd. for $\mathrm{C}_{16} \mathrm{H}_{12} \mathrm{O}_{4}$ : C, 71.64; $\mathrm{H}, 4.51 ; 0,23.86$. Found: $\mathrm{C}, 71.22 ; \mathrm{H}, 4.82 ; 0,24.01$.

\section{2-(4-chlorophenyl)-7-Hydroxy-4H-chromen-4-one (2d)}

White crystal, yield: $12 \%, \mathrm{mp}:>250^{\circ} \mathrm{C}$, IR $\left(\mathrm{KBr}, \mathrm{cm}^{-1}\right): 3278(\mathrm{OH}), 1645 ;{ }^{1} \mathrm{H}$ NMR $\left(500 \mathrm{MHz}, \mathrm{DMSO}-d_{6}\right): \delta$ $10.79(\mathrm{~s}, 1 \mathrm{H}, \mathrm{OH}), 8.10\left(\mathrm{~d}, J=8.7 \mathrm{~Hz}, 2 \mathrm{H}, \mathrm{H}_{2}^{\prime}, 6^{\prime}\right), 7.89\left(\mathrm{~d}, J=8.7 \mathrm{~Hz}, 1 \mathrm{H}, \mathrm{H}_{5}\right), 7.64\left(\mathrm{~d}, J=8.7 \mathrm{~Hz}, 2 \mathrm{H}, \mathrm{H}_{3^{\prime}, 5^{\prime}}\right), 7.01$ (d, $\left.J=2.1 \mathrm{~Hz}, 1 \mathrm{H}, \mathrm{H}_{8}\right), 6.95\left(\mathrm{~s}, 1 \mathrm{H}, \mathrm{H}_{3}\right), 6.93\left(\mathrm{~d}, J=2.1 \mathrm{~Hz}, 1 \mathrm{H}, \mathrm{H}_{6}\right)$. Anal. calcd. for $\mathrm{C}_{15} \mathrm{H}_{9} \mathrm{ClO}_{3}: \mathrm{C}, 66.07 ; \mathrm{H}$, $3.33 ; 0,17.60$. Found: $C, 65.89 ; H, 3.62 ; 0,17.33$.

\section{2-(4-bromophenyl)-7-Hydroxy-4H-chromen-4-one (2e)}

White crystal, yield:16\%, mp: $>250{ }^{\circ} \mathrm{C}$, IR $\left(\mathrm{KBr}, \mathrm{cm}^{-1}\right): 3301(\mathrm{OH}), 1607 ;{ }^{1} \mathrm{H}$ NMR $\left(500 \mathrm{MHz}, \mathrm{DMSO}-d_{6}\right): \delta$ $10.69(\mathrm{~s}, 1 \mathrm{H}, \mathrm{OH}), 8.02\left(\mathrm{~d}, J=8.7 \mathrm{~Hz}, 2 \mathrm{H}, \mathrm{H}_{2}^{\prime}, 6^{\prime}\right), 7.88\left(\mathrm{~d}, J=8.7 \mathrm{~Hz}, 1 \mathrm{H}, \mathrm{H}_{5}\right), 7.78\left(\mathrm{~d}, J=8.7 \mathrm{~Hz}, 2 \mathrm{H}, \mathrm{H}_{3^{\prime}, 5^{\prime}}\right), 6.99$ $\left(\mathrm{d}, J=2.1 \mathrm{~Hz}, 1 \mathrm{H}, \mathrm{H}_{8}\right), 6.94\left(\mathrm{~s}, 1 \mathrm{H}, \mathrm{H}_{3}\right), 6.92\left(\mathrm{dd}, J=8.7,2.1 \mathrm{~Hz}, 1 \mathrm{H}, \mathrm{H}_{6}\right)$. Anal. calcd. for $\mathrm{C}_{15} \mathrm{H}_{9} \mathrm{BrO}_{3}$ : C, 56.81; $H, 2.86 ; 0,15.13$. Found: $C, 56.63 ; H, 3.07 ; 0,15.43$.

\section{2-(2,3-dimethoxyphenyl)-7-Hydroxy-4H-chromen-4-one (2f)}

White crystal, yield:13\%, mp: $>250^{\circ} \mathrm{C}, \mathrm{IR}\left(\mathrm{KBr}, \mathrm{cm}^{-1}\right): 3005(\mathrm{OH}), 1627 ;{ }^{1} \mathrm{H}$ NMR $\left(500 \mathrm{MHz}, \mathrm{DMSO}-d_{6}\right): \delta$ $10.42(\mathrm{~s}, 1 \mathrm{H}, \mathrm{OH}), 7.90\left(\mathrm{~d}, J=8.7 \mathrm{~Hz}, 2 \mathrm{H}, \mathrm{H}_{5}\right), 7.32$ (dd, J=8.7, 2.1 Hz, 1H, $\left.\mathrm{H}_{6}\right), 7.19$ (dd, J=8.7, $2.1 \mathrm{~Hz}, 1 \mathrm{H}$, $\left.\mathrm{H}_{4^{\prime}}\right), 6.94\left(\mathrm{~d}, J=2.1 \mathrm{~Hz}, 1 \mathrm{H}, \mathrm{H}_{8}\right), 6.91-6.93\left(\mathrm{~m}, 2 \mathrm{H}, \mathrm{H}_{5^{\prime}, 6^{\prime}}\right), 6.61\left(\mathrm{~s}, 1 \mathrm{H}, \mathrm{H}_{3}\right), 3.88\left(\mathrm{~s}, 1 \mathrm{H}, \mathrm{OCH}_{3}\right), 3.82(\mathrm{~s}, 1 \mathrm{H}$, $\mathrm{OCH}_{3}$ ). Anal. calcd. for $\mathrm{C}_{17} \mathrm{H}_{14} \mathrm{O}_{5}: \mathrm{C}, 68.45 ; \mathrm{H}, 4.73 ; \mathrm{O}, 26.82$. Found: $\mathrm{C}, 68.18 ; \mathrm{H}, 5.01 ; 0,26.65$.

\section{2-(2,4-dimethoxyphenyl)-7-Hydroxy-4H-chromen-4-one (2g)}

White crystal, yield:15\%, mp: $>250^{\circ} \mathrm{C}, \mathrm{IR}\left(\mathrm{KBr}, \mathrm{cm}^{-1}\right): 2998(\mathrm{OH}), 1638 ;{ }^{1} \mathrm{H}$ NMR $\left(500 \mathrm{MHz}, \mathrm{DMSO}-d_{6}\right): \delta$ $10.35(\mathrm{~s}, 1 \mathrm{H}, \mathrm{OH}), 8.11\left(\mathrm{~d}, J=8.7 \mathrm{~Hz}, 1 \mathrm{H}, \mathrm{H}_{5}\right), 7.84\left(\mathrm{~d}, J=8.7 \mathrm{~Hz}, 1 \mathrm{H}, \mathrm{H}_{6}\right), 7.08\left(\mathrm{~s}, 1 \mathrm{H}, \mathrm{H}_{3}\right), 7.01(\mathrm{~d}, J=8.7 \mathrm{~Hz}$, 
$\left.1 \mathrm{H}, \mathrm{H}_{6}\right), 6.97\left(\mathrm{~s}, 2 \mathrm{H}, \mathrm{H}_{3^{\prime}}\right), 6.60\left(\mathrm{~d}, J=8.7 \mathrm{~Hz}, 1 \mathrm{H}, \mathrm{H}_{5^{\prime}}\right), 6.52\left(\mathrm{~s}, 1 \mathrm{H}, \mathrm{H}_{8}\right), 3.89\left(\mathrm{~s}, 1 \mathrm{H}, \mathrm{OCH}_{3}\right), 3.86\left(\mathrm{~s}, 1 \mathrm{H}, \mathrm{OCH}_{3}\right)$. Anal. calcd. for $\mathrm{C}_{17} \mathrm{H}_{14} \mathrm{O}_{5}$ : C, 68.45; $\mathrm{H}, 4.73 ; \mathrm{O}, 26.82$. Found: $\mathrm{C}, 68.76 ; \mathrm{H}, 4.41 ; 0,27.12$.

\section{2-(3,4-dimethoxyphenyl)-7-Hydroxy-4H-chromen-4-one (2h)}

White crystal, yield:17\%, mp: $>250^{\circ} \mathrm{C}, \mathrm{IR}\left(\mathrm{KBr}, \mathrm{cm}^{-1}\right): 3013(\mathrm{OH}), 1653 ;{ }^{1} \mathrm{H}$ NMR $\left(500 \mathrm{MHz}\right.$, DMSO- $\left.d_{6}\right): \delta$ $10.38(\mathrm{~s}, 1 \mathrm{H}, \mathrm{OH}), 7.94\left(\mathrm{~d}, J=8.7 \mathrm{~Hz}, 1 \mathrm{H}, \mathrm{H}_{5}\right), 7.70$ (dd, J=8.7, $\left.2.1 \mathrm{~Hz}, 1 \mathrm{H}, \mathrm{H}_{6}\right), 7.59\left(\mathrm{~s}, 1 \mathrm{H}, \mathrm{H}_{3}\right), 7.37$ (dd, $\left.J=8.7,2.1 \mathrm{~Hz}, 1 \mathrm{H}, \mathrm{H}_{6}\right), 7.11-7.14\left(\mathrm{~m}, 2 \mathrm{H}, \mathrm{H}_{2,}^{\prime} 5^{\prime}\right), 6.97\left(\mathrm{~s}, 1 \mathrm{H}, \mathrm{H}_{8}\right), 3.89\left(\mathrm{~s}, 1 \mathrm{H}, \mathrm{OCH}_{3}\right), 3.85\left(\mathrm{~s}, 1 \mathrm{H}, \mathrm{OCH}_{3}\right)$. Anal. calcd. for $\mathrm{C}_{17} \mathrm{H}_{14} \mathrm{O}_{5}: \mathrm{C}, 68.45 ; \mathrm{H}, 4.73 ; \mathrm{O}, 26.82$. Found: $\mathrm{C}, 68.09 ; \mathrm{H}, 4.98 ; 0,26.86$.

\section{7-Hydroxy-2-(2,3,4-trimethoxy phenyl)-4H-chromen-4-one (2i)}

White crystal, yield:26\%, mp: $>250^{\circ} \mathrm{C}, \mathrm{IR}\left(\mathrm{KBr}, \mathrm{cm}^{-1}\right): 3014(\mathrm{OH}), 1629 ;{ }^{1} \mathrm{H}$ NMR $\left(500 \mathrm{MHz}, \mathrm{DMSO}-d_{6}\right): \delta$ $10.80(\mathrm{~s}, 1 \mathrm{H}, \mathrm{OH}), 8.21\left(\mathrm{~d}, J=8.7 \mathrm{~Hz}, 1 \mathrm{H}, \mathrm{H}_{5}\right), 7.87\left(\mathrm{~d}, J=8.7 \mathrm{~Hz}, 1 \mathrm{H}, \mathrm{H}_{6}\right), 7.56\left(\mathrm{~d}, J=8.7 \mathrm{~Hz}, 1 \mathrm{H}, \mathrm{H}_{5}\right), 7.23(\mathrm{~s}$, $\left.1 \mathrm{H}, \mathrm{H}_{3}\right), 7.12-7.16\left(\mathrm{~m}, 1 \mathrm{H}, \mathrm{H}_{6}\right), 6.78\left(\mathrm{~s}, 1 \mathrm{H}, \mathrm{H}_{8}\right), 4.19\left(\mathrm{~s}, 1 \mathrm{H}, \mathrm{OCH}_{3}\right), 4.11\left(\mathrm{~s}, 1 \mathrm{H}, \mathrm{OCH}_{3}\right), 3.91\left(\mathrm{~s}, 1 \mathrm{H}, \mathrm{OCH}_{3}\right)$. Anal. calcd. for $\mathrm{C}_{18} \mathrm{H}_{16} \mathrm{O}_{6}$ : C, 65.85; $\mathrm{H}, 4.91 ; 0,29.24$. Found: $\mathrm{C}, 65.30 ; \mathrm{H}, 5.12 ; 0,29.40$.

\section{Synthesis of 4-oxo-2-phenyl-4H-chromen-7-yl methanesulfonate (3a-i)}

To a solution of 2a-i $(1 \mathrm{mmol})$ in dry tetrahydrofuran $(5 \mathrm{~mL})$ methanesulfonyl chloride $(1.5 \mathrm{mmol})$ and triethylamine $(2 \mathrm{mmol})$ was added dropwise in an ice bath and stirred at room temperature overnight. Then the volatiles were evaporated under vacuum. To this residue water was added and it was extracted with ethyl acetate. The organic phase was dried with sodium sulfate and the solvent was evaporated under vacuum. The product was purified by preparative TLC (hexane: EtOAc, 3:2).

\section{4-oxo-2-phenyl-4H-chromen-7-yl methanesulfonate (3a)}

White crystal, yield:67\%, mp:120-121 ${ }^{\circ} \mathrm{C}, \mathrm{IR}\left(\mathrm{KBr}, \mathrm{cm}^{-1}\right): 1638,1335$ (S=0), 1199; ${ }^{1} \mathrm{H} \mathrm{NMR}(500 \mathrm{MHz}$, DMSO- $d_{6}$ ): $\delta 8.17\left(\mathrm{~d}, J=8.4 \mathrm{~Hz}, 1 \mathrm{H}, \mathrm{H}_{5}\right), 8.15\left(\mathrm{~d}, J=8.4 \mathrm{~Hz}, 2 \mathrm{H}, \mathrm{H}_{2}, 6^{\prime}\right), 7.91\left(\mathrm{~d}, J=1.9 \mathrm{~Hz}, 1 \mathrm{H}, \mathrm{H}_{8}\right)$, 7.67-7.59 $\left(\mathrm{m}, 3 \mathrm{H}, \mathrm{H}_{3^{\prime}, 4^{\prime}, 5^{\prime}}\right), 7.50\left(\mathrm{dd}, \mathrm{J}=8.4,1.9 \mathrm{~Hz}, 1 \mathrm{H}, \mathrm{H}_{6}\right), 7.13\left(\mathrm{~s}, 1 \mathrm{H}, \mathrm{H}_{3}\right), 3.55\left(\mathrm{~s}, 3 \mathrm{H}, \mathrm{CH}_{3} \mathrm{SO}_{2}\right)$. Anal. calcd. for $\mathrm{C}_{16} \mathrm{H}_{12} \mathrm{O}_{5} \mathrm{~S}: \mathrm{C}, 60.75 ; \mathrm{H}, 3.82 ; \mathrm{O}, 25.29$. Found: C, 60.81; $\mathrm{H}, 4.02 ; 0,25.53$.

\section{2-(4-methyl phenyl)-4-oxo-4H-chromen-7-yl methanesulfonate (3b)}


White crystal, yield:69\%, mp:184-185 ${ }^{\circ} \mathrm{C}$, IR $\left(\mathrm{KBr}, \mathrm{cm}^{-1}\right): 1642,1342$ (S=0), $1177 ;{ }^{1} \mathrm{H}$ NMR $(500 \mathrm{MHz}$, DMSO- $d_{6}$ ): $\delta 8.15\left(\mathrm{~d}, J=8.7 \mathrm{~Hz}, 1 \mathrm{H}, \mathrm{H}_{5}\right), 8.06\left(\mathrm{~d}, J=8.7 \mathrm{~Hz}, 2 \mathrm{H}, \mathrm{H}_{2,6} \mathrm{6}^{\prime}\right), 7.91$ (d, J=2.2 Hz, 1H, $\mathrm{H}_{8}$ ), 7.48 (dd, $\left.J=8.7,2.2 \mathrm{~Hz}, 1 \mathrm{H}, \mathrm{H}_{6}\right), 7.42\left(\mathrm{dd}, J=8.7,2.2 \mathrm{~Hz}, 1 \mathrm{H}, \mathrm{H}_{3^{\prime}, 5^{\prime}}\right), 7.08\left(\mathrm{~s}, 1 \mathrm{H}, \mathrm{H}_{3}\right), 3.55\left(\mathrm{~s}, 3 \mathrm{H}, \mathrm{CH}_{3} \mathrm{SO}_{2}\right), 2.83(\mathrm{~s}, 3 \mathrm{H}$, $\left.\mathrm{CH}_{3}\right),{ }^{13} \mathrm{C}$ NMR $\left(125 \mathrm{MHz}\right.$, DMSO-d $\left.d_{6}\right): 177.0 \mathrm{C}_{4}, 163.9 \mathrm{C}_{2}, 156.6 \mathrm{C}_{8 \mathrm{a}}, 152.9 \mathrm{C}_{7}, 142.88 \mathrm{C}_{4^{\prime}}, 130.2 \mathrm{C}_{3^{\prime}, 5^{\prime}}$

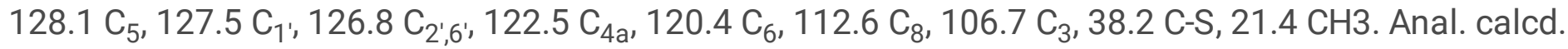
for $\mathrm{C}_{17} \mathrm{H}_{14} \mathrm{O}_{5} \mathrm{~S}$ : $\mathrm{C}, 61.81 ; \mathrm{H}, 4.27 ; 0,24.22$. Found: $\mathrm{C}, 61.48 ; \mathrm{H}, 4.43 ; 0,24.18$.

\section{2-(4-methoxy phenyl)-4-oxo-4H-chromen-7-yl methanesulfonate (3c)}

White crystal, yield:78\%, mp:208-212 ${ }^{\circ} \mathrm{C}$, IR $\left(\mathrm{KBr}, \mathrm{cm}^{-1}\right): 1637,1363$ (S=0), 1179; ${ }^{1} \mathrm{H}$ NMR $(500 \mathrm{MHz}$, DMSO- $\left.d_{6}\right): \delta 8.13\left(\mathrm{~d}, J=8.7 \mathrm{~Hz}, 1 \mathrm{H}, \mathrm{H}_{5}\right), 8.09\left(\mathrm{~d}, J=8.9 \mathrm{~Hz}, 2 \mathrm{H}, \mathrm{H}_{3^{\prime}, 5}\right), 7.85\left(\mathrm{~d}, J=2.2 \mathrm{~Hz}, 1 \mathrm{H}, \mathrm{H}_{8}\right), 7.46(\mathrm{~d}$, $\left.J=8.7 \mathrm{~Hz}, 1 \mathrm{H}, \mathrm{H}_{6}\right), 7.13\left(\mathrm{~d}, J=8.9 \mathrm{~Hz}, 2 \mathrm{H}, \mathrm{H}_{2}{ }^{\prime} 6^{\prime}\right), 6.98\left(\mathrm{~s}, 1 \mathrm{H}, \mathrm{H}_{3}\right), 3.87\left(\mathrm{~s}, 3 \mathrm{H}, \mathrm{OCH}_{3}\right), 3.52\left(\mathrm{~s}, 3 \mathrm{H}, \mathrm{CH}_{3} \mathrm{SO}_{2}\right)$,

${ }^{13} \mathrm{C}$ NMR $\left(125 \mathrm{MHz}\right.$, DMSO- $\left.d_{6}\right): 176.7 \mathrm{C}_{4}, 163.6 \mathrm{C}_{2}, 163 \mathrm{C}_{4^{\prime}}, 156.6 \mathrm{C}_{8 \mathrm{a}}, 153 \mathrm{C}_{7}, 128.7 \mathrm{C}_{2^{\prime}, 6^{\prime},}, 127.5 \mathrm{C}_{5}, 123.3$ $\mathrm{C}_{1}, 122.8 \mathrm{C}_{4 a}, 120.5 \mathrm{C}_{6}, 115.1 \mathrm{C}_{3^{\prime}, 5^{\prime}}, 112.7 \mathrm{C}_{8}, 106.0 \mathrm{C}_{3}, 56.0 \mathrm{C}-0,37.4 \mathrm{C}-\mathrm{S}$. Anal. calcd. for $\mathrm{C}_{17} \mathrm{H}_{14} \mathrm{O}_{6} \mathrm{~S}: \mathrm{C}$, 58.95; $\mathrm{H}, 4.07 ; \mathrm{O}, 27.72$. Found: $\mathrm{C}, 59.22 ; \mathrm{H}, 4.33 ; \mathrm{O}, 28.10$.

\section{2-(4-chloro phenyl)-4-oxo-4H-chromen-7-yl methanesulfonate (3d)}

White crystal, yield:71\%, mp:201-203 ${ }^{\circ} \mathrm{C}, \mathrm{IR}\left(\mathrm{KBr}, \mathrm{cm}^{-1}\right)$ : 1636, 1340 (S=0), 1179; ${ }^{1} \mathrm{H}$ NMR $(500 \mathrm{MHz}$, DMSO- $d_{6}$ ): $\delta 8.19\left(\mathrm{~d}, J=8.7 \mathrm{~Hz}, 2 \mathrm{H}, \mathrm{H}_{2^{\prime}, 6^{\prime}}\right), 8.16\left(\mathrm{~d}, J=8.7 \mathrm{~Hz}, 1 \mathrm{H}, \mathrm{H}_{5}\right), 7.92\left(\mathrm{~d}, J=2.2 \mathrm{~Hz}, 1 \mathrm{H}, \mathrm{H}_{8}\right), 7.69$ (d, $\left.J=8.7 \mathrm{~Hz}, 2 \mathrm{H}, \mathrm{H}_{3^{\prime}, 5^{\prime}}\right), 7.50\left(\mathrm{dd}, J=8.7,2.2 \mathrm{~Hz}, 1 \mathrm{H}, \mathrm{H}_{6}\right), 7.16\left(\mathrm{~s}, 1 \mathrm{H}, \mathrm{H}_{3}\right), 3.55\left(\mathrm{~s}, 3 \mathrm{H}, \mathrm{CH}_{3} \mathrm{SO}_{2}\right) ; \mathrm{MS}: \mathrm{m} / \mathrm{z} 350$ $[\mathrm{M}+1]$. Anal. calcd. for $\mathrm{C}_{16} \mathrm{H}_{11} \mathrm{ClO}_{5} \mathrm{~S}$ : $\mathrm{C}, 54.78 ; \mathrm{H}, 3.16 ; \mathrm{O}, 22.81$. Found: $\mathrm{C}, 54.42 ; \mathrm{H}, 3.33 ; 0,23.01$.

\section{2-(4-bromo phenyl)-4-oxo-4H-chromen-7-yl methanesulfonate (3e)}

White crystal, yield:65\%, mp:229-230 ${ }^{\circ} \mathrm{C}, \mathrm{IR}\left(\mathrm{KBr}, \mathrm{cm}^{-1}\right): 1640,1340(\mathrm{~S}=0), 1178 ;{ }^{1} \mathrm{H}$ NMR $(500 \mathrm{MHz}$, DMSO- $\left.d_{6}\right): \delta 8.16\left(\mathrm{~d}, J=8.7 \mathrm{~Hz}, 1 \mathrm{H}, \mathrm{H}_{5}\right), 8.11\left(\mathrm{~d}, J=8.7 \mathrm{~Hz}, 1 \mathrm{H}, \mathrm{H}_{2}{ }^{\prime} 6^{\prime}\right), 7.92\left(\mathrm{~d}, J=2.2 \mathrm{~Hz}, 1 \mathrm{H}, \mathrm{H}_{8}\right), 7.83(\mathrm{~d}$, $\left.J=8.7 \mathrm{~Hz}, 2 \mathrm{H}, \mathrm{H}_{3^{\prime}, 5^{\prime}}\right), 7.50\left(\mathrm{dd}, J=8.7,2.2 \mathrm{~Hz}, 1 \mathrm{H}, \mathrm{H}_{6}\right), 7.17\left(\mathrm{~s}, 1 \mathrm{H}, \mathrm{H}_{3}\right), 3.55\left(\mathrm{~s}, 3 \mathrm{H}, \mathrm{CH}_{3} \mathrm{SO}_{2}\right) ; \mathrm{MS}: \mathrm{m} / \mathrm{z} 395$ $[\mathrm{M}+1]$. Anal. calcd. for $\mathrm{C}_{16} \mathrm{H}_{11} \mathrm{BrO}_{5} \mathrm{~S}$ : $\mathrm{C}, 48.62 ; \mathrm{H}, 2.81 ; 0,22.24$. Found: $\mathrm{C}, 48.43 ; \mathrm{H}, 3.13 ; 0,22.56$.

\section{2-(2,3-dimethoxy phenyl)-4-oxo-4H-chromen-7-yl methanesulfonate (3f)}


White crystal, yield:78\%, mp:208-212 ${ }^{\circ} \mathrm{C}$, IR $\left(\mathrm{KBr}, \mathrm{cm}^{-1}\right): 1648,1368(\mathrm{~S}=0), 1149 ;{ }^{1} \mathrm{H}$ NMR $(500 \mathrm{MHz}$, DMSO$\left.d_{6}\right): \delta 8.17\left(\mathrm{~d}, J=8.7 \mathrm{~Hz}, 1 \mathrm{H}, \mathrm{H}_{5}\right), 7.82\left(\mathrm{~d}, J=2.2 \mathrm{~Hz}, 1 \mathrm{H}, \mathrm{H}_{8}\right), 7.50\left(\mathrm{dd}, J=8.9,2.2 \mathrm{~Hz}, 1 \mathrm{H}, \mathrm{H}_{6}\right), 7.42(\mathrm{~d}, J=2.2$ $\left.\mathrm{Hz}, 1 \mathrm{H}, \mathrm{H}_{4^{\prime}}\right), 7.26-7.33\left(\mathrm{~m}, 2 \mathrm{H}, \mathrm{H}_{5^{\prime}, 6^{\prime}}\right), 6.83\left(\mathrm{~s}, 1 \mathrm{H}, \mathrm{H}_{3}\right), 3.89\left(\mathrm{~s}, 3 \mathrm{H}, \mathrm{OCH}_{3}\right), 3.84\left(\mathrm{~s}, 3 \mathrm{H}, \mathrm{OCH}_{3}\right), 3.53(\mathrm{~s}, 3 \mathrm{H}$, $\left.\mathrm{CH}_{3} \mathrm{SO}_{2}\right) ;$ ); ${ }^{13} \mathrm{C}$ NMR $\left(125 \mathrm{MHz}\right.$, DMSO-d $\left.d_{6}\right): 177.2 \mathrm{C}_{4}, 163.9 \mathrm{C}_{2}, 161.9 \mathrm{C}_{8 \mathrm{a}}, 161.0 \mathrm{C}_{7}, 157.0 \mathrm{C}_{3^{\prime}}, 155.9 \mathrm{C}_{2}$, $131.1 C_{5}, 120.8 C_{1}, 120.6 C_{5^{\prime}}, 117.7 C_{6^{\prime}}, 114.9 C_{4 a}, 112.5 C_{4^{\prime}}, 110.9 C_{3}, 110.0 C_{6}, 105.1 C_{8}, 59.5 C_{-} 0_{2}, 58.5$ $\mathrm{C}-\mathrm{O}_{3}, 42.0$ C-S. Anal. calcd. for $\mathrm{C}_{18} \mathrm{H}_{16} \mathrm{O}_{7} \mathrm{~S}$ : $\mathrm{C}, 57.44 ; \mathrm{H}, 4.28 ; \mathrm{O}, 29.76$. Found: $\mathrm{C}, 57.73 ; \mathrm{H}, 4.56 ; 0,30.03$.

\section{2-(2,4-dimethoxy phenyl)-4-oxo-4H-chromen-7-yl methanesulfonate $(3 \mathrm{~g})$}

White crystal, yield:78\%, mp:208-212 ${ }^{\circ} \mathrm{C}$, IR $\left(\mathrm{KBr}, \mathrm{cm}^{-1}\right): 1659,1349(\mathrm{~S}=0), 1133 ;{ }^{1} \mathrm{H}$ NMR $(500 \mathrm{MHz}$, DMSO- $d_{6}$ ): $\delta 8.06\left(\mathrm{~d}, J=8.7 \mathrm{~Hz}, 1 \mathrm{H}, \mathrm{H}_{5}\right), 7.94\left(\mathrm{dd}, J=8.9,2.2 \mathrm{~Hz}, 1 \mathrm{H}, \mathrm{H}_{6}\right), 7.62\left(\mathrm{~d}, J=2.2,1 \mathrm{H}, \mathrm{H}_{8}\right), 7.56(\mathrm{~d}$, $\left.J=2.2 \mathrm{~Hz}, 1 \mathrm{H}, \mathrm{H}_{3^{\prime}}\right), 7.51\left(\mathrm{dd}, J=8.9,2.2 \mathrm{~Hz}, 1 \mathrm{H}, \mathrm{H}_{6}\right), 7.27\left(\mathrm{dd}, J=8.9,2.2 \mathrm{~Hz}, 1 \mathrm{H}, \mathrm{H}_{5^{\prime}}\right), 4.02\left(\mathrm{~s}, 3 \mathrm{H}, \mathrm{OCH}_{3}\right)$, $3.95\left(\mathrm{~s}, 3 \mathrm{H}, \mathrm{OCH}_{3}\right), 3.50\left(\mathrm{~s}, 3 \mathrm{H}, \mathrm{CH}_{3} \mathrm{SO}_{2}\right) ;$ ); ${ }^{13} \mathrm{C} \mathrm{NMR}\left(125 \mathrm{MHz}, \mathrm{DMSO}-d_{6}\right): 178.3 \mathrm{C}_{4}, 163.0 \mathrm{C}_{2}, 162.8 \mathrm{C}_{4^{\prime}}$, $160.4 C_{2}, 159.4 C_{8 a}, 157.9 C_{7}, 130.2 C_{6^{\prime}}, 128.7 C_{5}, 117.7 C_{4 a}, 114.4 C_{1^{\prime}}, 113.4 C_{3}, 111.0 C_{6}, 106.1 C_{5^{\prime}}, 105.1$

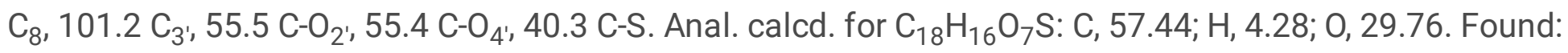
C, $57.61 ; \mathrm{H}, 4.55 ; 0,29.98$.

\section{2-(3,4-dimethoxy phenyl)-4-oxo-4H-chromen-7-yl methanesulfonate (3h)}

White crystal, yield:78\%, mp:208-212 ${ }^{\circ} \mathrm{C}$, IR $\left(\mathrm{KBr}, \mathrm{cm}^{-1}\right): 1655,1329(\mathrm{~S}=0), 1169 ;{ }^{1} \mathrm{H}$ NMR $(500 \mathrm{MHz}$, DMSO- $\left.\left.d_{6}\right): \delta 7.94\left(\mathrm{~d}, J=8.7 \mathrm{~Hz}, 1 \mathrm{H}, \mathrm{H}_{5}\right), 7.70\left(\mathrm{~d}, J=8.9 \mathrm{~Hz}, 1 \mathrm{H}, \mathrm{H}_{6}\right)^{\prime}\right), 7.59\left(\mathrm{~s}, 1 \mathrm{H}, \mathrm{H}_{8}\right), 7.37(\mathrm{~d}, J=8.7 \mathrm{~Hz}, 1 \mathrm{H}$, $\left.\mathrm{H}_{6}\right)$, 7.11-7.15 (m, 2H, $\left.\mathrm{H}_{2,5} 5^{\prime}\right), 6.98\left(\mathrm{~s}, 1 \mathrm{H}, \mathrm{H}_{3}\right), 4.01\left(\mathrm{~s}, 3 \mathrm{H}, \mathrm{OCH}_{3}\right), 3.89\left(\mathrm{~s}, 3 \mathrm{H}, \mathrm{OCH}_{3}\right), 3.85\left(\mathrm{~s}, 3 \mathrm{H}, \mathrm{CH}_{3} \mathrm{SO}_{2}\right)$; ${ }^{13} \mathrm{C}$ NMR $\left(125 \mathrm{MHz}\right.$, DMSO- $\left.d_{6}\right): 178.9 \mathrm{C}_{4}, 165 \mathrm{C}_{2}, 160.0 \mathrm{C}_{8 \mathrm{a}}, 157.6 \mathrm{C}_{7}, 154.2 \mathrm{C}_{3^{\prime}}, 149.3 \mathrm{C}_{4^{\prime}}, 130.0 \mathrm{C}_{5}, 128.0$ $\mathrm{C}_{1^{\prime}}, 127.5 \mathrm{C}_{6^{\prime}}, 126.8 \mathrm{C}_{4 a}, 112.5 \mathrm{C}_{5^{\prime}}, 108 \mathrm{C}_{6}, 105.2 \mathrm{C}_{2^{\prime}}, 104.5 \mathrm{C}_{8}, 103.9 \mathrm{C}_{3}, 56.9 \mathrm{C}-\mathrm{O}_{3^{\prime}}, 57.4 \mathrm{C}-\mathrm{O}_{4^{\prime}}, 42.4 \mathrm{C}-\mathrm{S}$. Anal. calcd. for $\mathrm{C}_{18} \mathrm{H}_{16} \mathrm{O}_{7} \mathrm{~S}$ : $\mathrm{C}, 57.44 ; \mathrm{H}, 4.28 ; 0,29.76$. Found: $\mathrm{C}, 57.09 ; \mathrm{H}, 4.46 ; 0,29.88$.

\section{4-oxo-2-(2,3,4-trimethoxy phenyl)-4H-chromen-7-yl methanesulfonate (3i)}

White crystal, yield:78\%, mp:208-212 ${ }^{\circ} \mathrm{C}, \mathrm{IR}\left(\mathrm{KBr}, \mathrm{cm}^{-1}\right)$ : 1680, $1328(\mathrm{~S}=0), 1145 ;{ }^{1} \mathrm{H}$ NMR $(500 \mathrm{MHz}$, DMSO- $\left.d_{6}\right): \delta 8.15\left(\mathrm{~d}, J=8.7 \mathrm{~Hz}, 1 \mathrm{H}, \mathrm{H}_{5}\right), 7.81\left(\mathrm{~s}, 1 \mathrm{H}, \mathrm{H}_{8}\right), 7.67\left(\mathrm{~d}, J=8.7 \mathrm{~Hz}, 1 \mathrm{H}, \mathrm{H}_{6}\right), 7.47(\mathrm{~d}, J=8.9 \mathrm{~Hz}, 1 \mathrm{H}$, $\left.\mathrm{H}_{6^{\prime}}\right), 7.03\left(\mathrm{~d}, \mathrm{~J}=8.9 \mathrm{~Hz}, 1 \mathrm{H}, \mathrm{H}_{5^{\prime}}\right), 6.84\left(\mathrm{~s}, 1 \mathrm{H}, \mathrm{H}_{3}\right), 3.89\left(\mathrm{~s}, 3 \mathrm{H}, \mathrm{OCH}_{3}\right), 3.84\left(\mathrm{~s}, 3 \mathrm{H}, \mathrm{OCH}_{3}\right), 3.81\left(\mathrm{~s}, 3 \mathrm{H}, \mathrm{OCH}_{3}\right)$, $3.53\left(\mathrm{~s}, 3 \mathrm{H}, \mathrm{CH}_{3} \mathrm{SO}_{2}\right) ;{ }^{13} \mathrm{C} \mathrm{NMR}\left(125 \mathrm{MHz}, \mathrm{DMSO}-d_{6}\right): 178.8 \mathrm{C}_{4}, 168.5 \mathrm{C}_{2}, 157.5 \mathrm{C}_{8 \mathrm{a}}, 157 \mathrm{C}_{7}, 154.6 \mathrm{C}_{4^{\prime}}$, $152.9 C_{2^{\prime}}, 141.9 C_{3^{\prime}}, 129.0 C_{5}, 122.7 C_{6^{\prime}}, 119.5 C_{1^{\prime}}, 118.9 C_{4 a}, 110.3 C_{3}, 109.0 C_{6}, 107.5 C_{5^{\prime}}, 103.0 C_{8}, 56.6$ 


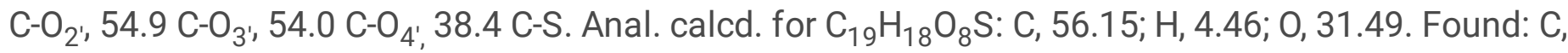
$56.55 ; \mathrm{H}, 4.87 ; 0,31.73$.

\subsection{Cell culture}

A human breast cancer cell line, MCF-7, was obtained from the Iranian Biological Resource Center (Tehran, Iran) and maintained in RPMI 1640 medium (Biowest). The medium was supplemented with $10 \%$ fetal bovine serum (FBS) (Gibco, Carlsbad, CA, USA) and 1\% antibiotics (Penicillin and Streptomycin). The cells were incubated at $37{ }^{\circ} \mathrm{C}$ under the standard condition of $95 \%$ humidity and $5 \%$ $\mathrm{CO}_{2}$ to reach $70 \%$ cell confluency [24].

\subsection{Cell proliferation assay}

The cytotoxicity of compounds was assessed by MTT assay which measures the percentage of viable cells. Cells were seeded in a 96-well cell culture plate at $7 \times 10^{3}$ cells $/$ well and incubated for $48 \mathrm{~h}$. Then, cells were exposed to fresh medium containing different concentrations of compounds. Subsequently, the medium was replaced with tetrazolium salt (5 mg/ml of PBS) (MTT, (3-(4, 5-dimethylthiazol-2-yl)-2, 5diphenyltetrazolium bromide) (Sigma, St.Louis, MO, USA) followed by additional $4 \mathrm{~h}$ incubation at $37^{\circ} \mathrm{C}$. The formed formazan crystals were dissolved in $100 \mu \mathrm{l}$ of Dimethyl sulfoxide (DMSO) (Merck) and measured for absorbance at $570 \mathrm{~nm}$ using a plate reader (BioRad, Model 680). Also finally, $\mathrm{IC}_{50}$ values were defined as the half-maximal inhibitory concentration.

\subsection{Flow cytometry analysis of cellular apoptosis}

The Annexin V-FITC/PI (Propidium iodide) dual staining assay (BD Pharmingen ${ }^{\text {TM }}$ kit) was used to determine the induction of apoptosis by the most potent compound $3 \mathrm{c}$, in comparison with commercial anticancer drug docetaxel. The breast cancer cell line MCF-7 $\left(3 \times 10^{5}\right.$ cells/well) were seeded into 6-well plates and incubated overnight at $37^{\circ} \mathrm{C}$ under $5 \% \mathrm{CO}_{2}$ overnight. After treatment the cells with $\mathrm{IC}_{50}$ concentrations of compound 3c, docetaxel as positive control, and 1\% DMSO as negative control, incubated with for $24 \mathrm{~h}$. Then, the treated cells were trypsinized, harvested and washed with PBS ( $\mathrm{pH} 7.4)$. The cell suspension was centrifuged at 1200 and resuspended in $500 \mu \mathrm{l}$ of $1 \times$ annexin $V$ binding buffer containing 1.4 M NaCl, $25 \mathrm{mM} \mathrm{CaCl}_{2}, 0.1 \mathrm{M} \mathrm{HEPES/} \mathrm{NaOH}$ (pH 7.4). The cells were double stained with 5 $\mu \mathrm{L}$ of Annexin V-PE and $5 \mu \mathrm{L}$ of PI solution and incubated at room temperature in dark for 15 mins. After adding $400 \mu \mathrm{L}$ of $1 \times$ annexin binding buffer to the vials, the cells were analyzed by flow cytometry using FITC signal detector (FL1) and PI staining by the phycoerythrin emission signal detector (FL2) [25].

\subsection{Docking analysis}


To determine the possible binding modes of the compound, docking analysis was carried out against the STS enzyme using the smina molecular docking The X-ray crystal structures of STS enzyme (PID: 1P49) were extracted from the PBD site and were prepared by removing solvent molecules and the cocrystallized ligands. Polar hydrogen atoms were added to the enzymes and the Kollmann charges were assigned. The compound (3c) was drawn using Marvin Sketch and subjected to energy minimization using the steepest descent algorithm and then Gasteiger charges were calculated by Open Babel. Binding sites were determined automatically using the coordinates of native co-crystallized ligands of enzymes [26].

\section{Declarations}

\section{Funding}

This is to acknowledge any financial interest or benefit that has arisen from the direct applications of this research.

\section{Conflicts of interest/Competing interests}

The authors declare that they have no competing interests.

\section{Availability of data and material}

The datasets used and analyzed during the current study are available from the corresponding author on reasonable request.

\section{Authors' contributions}

M.H.J., contributed to the synthesis and characterization of compounds; A.I., contributed to the designing and preparation of the manuscript; M.S., contributed to the apoptosis inducing activity evaluation of compounds; H.M., contributed to the designing and cytotoxicity evaluation of compounds and preparation of the related part in manuscript; P.T., contributed to the cytotoxicity evaluation of compounds; S.E. contributed to the cytotoxicity evaluation of compounds; L.N. supervised all phases of the study; S.S.M. supervised all phases of the study.

\section{Consent to participate}

Not applicable. 


\section{Consent for publication}

Not applicable.

\section{References}

1. society agac (2018) cancer facts and figures. american cancer society:1

2. Ferlay HSFBDFCMDPIJCJ (2010) Estimates of worldwide burden of cancer in 2008, GLOBOCAN 2008. Int J Cancer: 2893-2917

3. Pasqualini JR (2004) The selective estrogen enzyme modulators in breast cancer: a review. Biochim Biophys:123-143

4. Deroo BJ, Korach KS (2006) Estrogen receptors and human disease. The Journal of clinical investigation 116 (3):561-570

5. Saha T, Makar S, Swetha R, Gutti G, Singh SK (2019) Estrogen signaling: An emanating therapeutic target for breast cancer treatment. European Journal of Medicinal Chemistry 177:116-143. doi:https://doi.org/10.1016/j.ejmech.2019.05.023

6. Ireson CR, Chander SK, Purohit A, Parish DC, Woo LWL, Potter BVL (2004) Pharmacokinetics of the nonsteroidal steroid sulphatase inhibitor 667 COUMATEand its sequestration into red blood cells in rats. Br J Cancer 91:1399-1404

7. Reed MJ1 PA, Woo LW, Newman SP, Potter BV. (2005) Steroid sulfatase: molecular biology, regulation, and inhibition. Endocr Rev:171-202

8. Reed M, Purohit A, Woo LL, Newman SP, Potter BV (2005) Steroid sulfatase: molecular biology, regulation, and inhibition. Endocrine reviews 26 (2):171-202

9. Rižner TL (2016) The Important Roles of Steroid Sulfatase and Sulfotransferases in Gynecological Diseases. Frontiers in Pharmacology 7 (30). doi:10.3389/fphar.2016.00030

10. Geisler J, Sasano H, Chen S, Purohit A (2011) Steroid sulfatase inhibitors: Promising new tools for breast cancer therapy? The Journal of Steroid Biochemistry and Molecular Biology 125 (1):39-45. doi:https://doi.org/10.1016/j.jsbmb.2011.02.002

11. Daśko M, Demkowicz S, Biernacki K, Ciupak O, Kozak W, Masłyk M, Rachon J (2020) Recent progress in the development of steroid sulphatase inhibitors - examples of the novel and most promising compounds from the last decade. Journal of Enzyme Inhibition and Medicinal Chemistry 35 (1):1163-1184. doi:10.1080/14756366.2020.1758692

12. A. Thakur RSaVJ (Eur. J. Med. Chem.) Coumarins as anticancer agents: a review on synthetic strategies, mechanism of action and SAR studies. Eur J Med Chem 101:476-495

13. Purohit A, Dauvois S, Parker MG, Potter BVL, Williams GJ, Reed MJ (1994) The hydrolysis of oestrone sulphate and dehydroepiandrosterone sulphate by human steroid sulphatase expressed in transfected COS-1 cells. The Journal of Steroid Biochemistry and Molecular Biology 50 (1):101-104. doi:https://doi.org/10.1016/0960-0760(94)90177-5 
14. Purohit A, Williams GJ, Howarth NM, Potter BVL, Reed MJ (1995) Inactivation of steroid sulfatase by an active site-directed inhibitor, estrone-3-0-sulfamate. Biochemistry:11508-11514

15. Potter MPTaBVL (2015) Discovery and Development of the Aryl O-Sulfamate Pharmacophore for Oncology and Women's Health. J Med Chem:7634-7658

16. Kozak W, Daśko M, Masłyk M, Pieczykolan JS, Gielniewski B, J. R, S. D (2014) Phosphate tricyclic coumarin analogs as steroid sulfatase inhibitors: synthesis and biological activity. RSC Adv:4435044358

17. Demkowicz S, Kozak W, Daśko M, Masłyk M, Gielniewski B, Rachon J (2015) Synthesis of bicoumarin thiophosphate derivatives as steroid sulfatase inhibitors. Eur J Med chem:358-366

18. Nussbaumer P, Billich A (2004) Steroid sulfatase inhibitors. Medicinal research reviews 24 (4):529576

19. Reed MJ, Potter BVL (2003) Compounds that inhibit oestrone sulphatase and/or aromatase and methods for making and using. Google Patents,

20. P. Nussbaumer PL, A. Billich, (2002) 2-Substituted 4-(thio) chromenone 6-Osulfamates:potent inhibitors of human steroid sulfatase. J Med Chem:4310-4320

21. P. Nussbaumer APW, A. Billich, (2003) Estrogenic potential of 2-alkyl-4-(thio) chromenone 6-0sulfamates: potent inhibitors of human steroid sulfatase. J Med Chem:5091-5094

22. Thomas MP, Potter BVL (2015) Discovery and development of the aryl O-sulfamate pharmacophore for oncology and women's health. J Med Chem:7634-7658

23. Reed MJ, Purohit A, Woo LWL, Newman SP, Potter BVL (2005) Stroid sulfatase: Molecular biology, regulation, and inhibition. Endocr Rev:171-202

24. Edraki N, Iraji A, Firuzi O, Fattahi Y, Mahdavi M, Foroumadi A, Khoshneviszadeh M, Shafiee A, Miri R (2016) 2-Imino 2H-chromene and 2-(phenylimino) 2H-chromene 3-aryl carboxamide derivatives as novel cytotoxic agents: synthesis, biological assay, and molecular docking study. Journal of the Iranian Chemical Society 13 (12):2163-2171. doi:10.1007/s13738-016-0934-7

25. Abolhasani MH, Safavi M, Goodarzi MT, Kassaee SM, Azin M (2018) Identification and anti-cancer activity in 2D and 3D cell culture evaluation of an Iranian isolated marine microalgae Picochlorum sp. RCC486. DARU Journal of Pharmaceutical Sciences 26 (2):105-116

26. Saeedi M, Rastegari A, Hariri R, Mirfazli SS, Mahdavi M, Edraki N, Firuzi O, Akbarzadeh T (2020) Design and synthesis of novel arylisoxazole-chromenone carboxamides: Investigation of biological activities associated with Alzheimer's disease. Chemistry \& biodiversity 17 (5):e1900746

\section{Tables}

Due to technical limitations, tables are only available as a download in the Supplemental Files section.

\section{Figures}




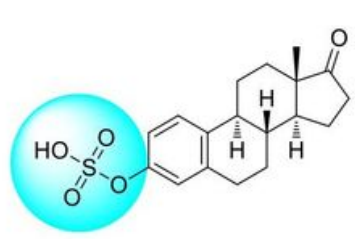

(A)

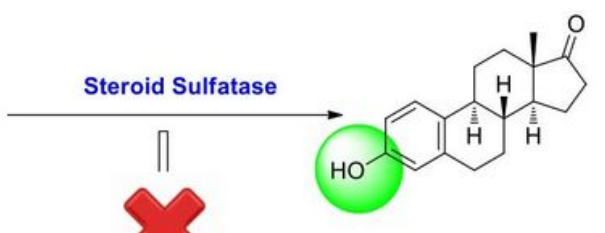

(B)

Steroid Sulfatase Inhibiors

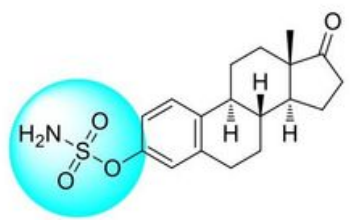

(C) EMATE

oestrone-3-O-sulphamate

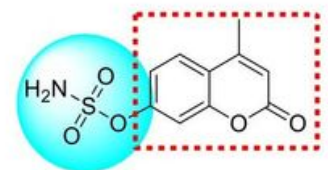

(G) COUMATE

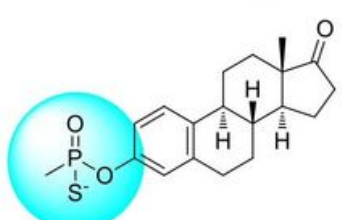

(D)

oestrone 3-O-methylphosphonothioate

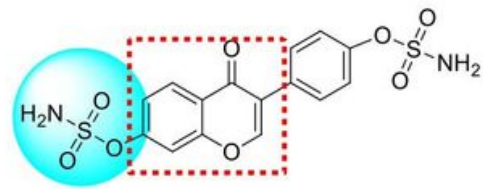

(H)

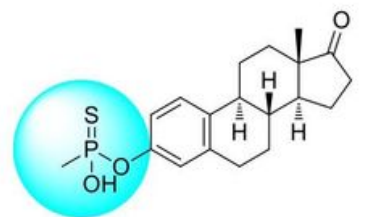

(E)

oestrone 3-methylthiophosphonate

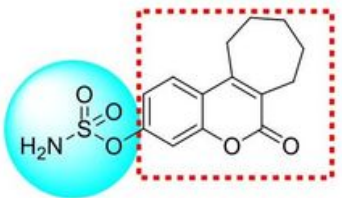

(l) COUMATE 667

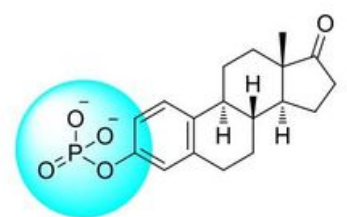

(F)

oestrone 3-phosphate

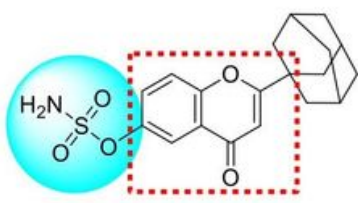

(j)

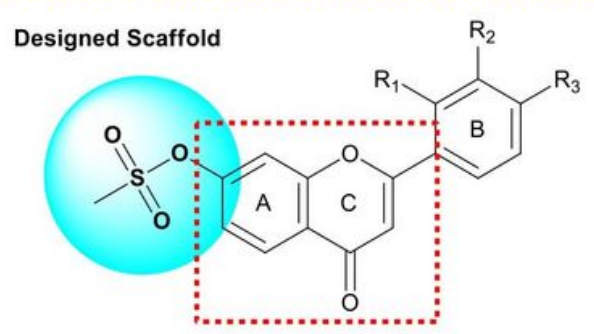

Figure 1

Structures of most potent STS inhibitors and designed compound 


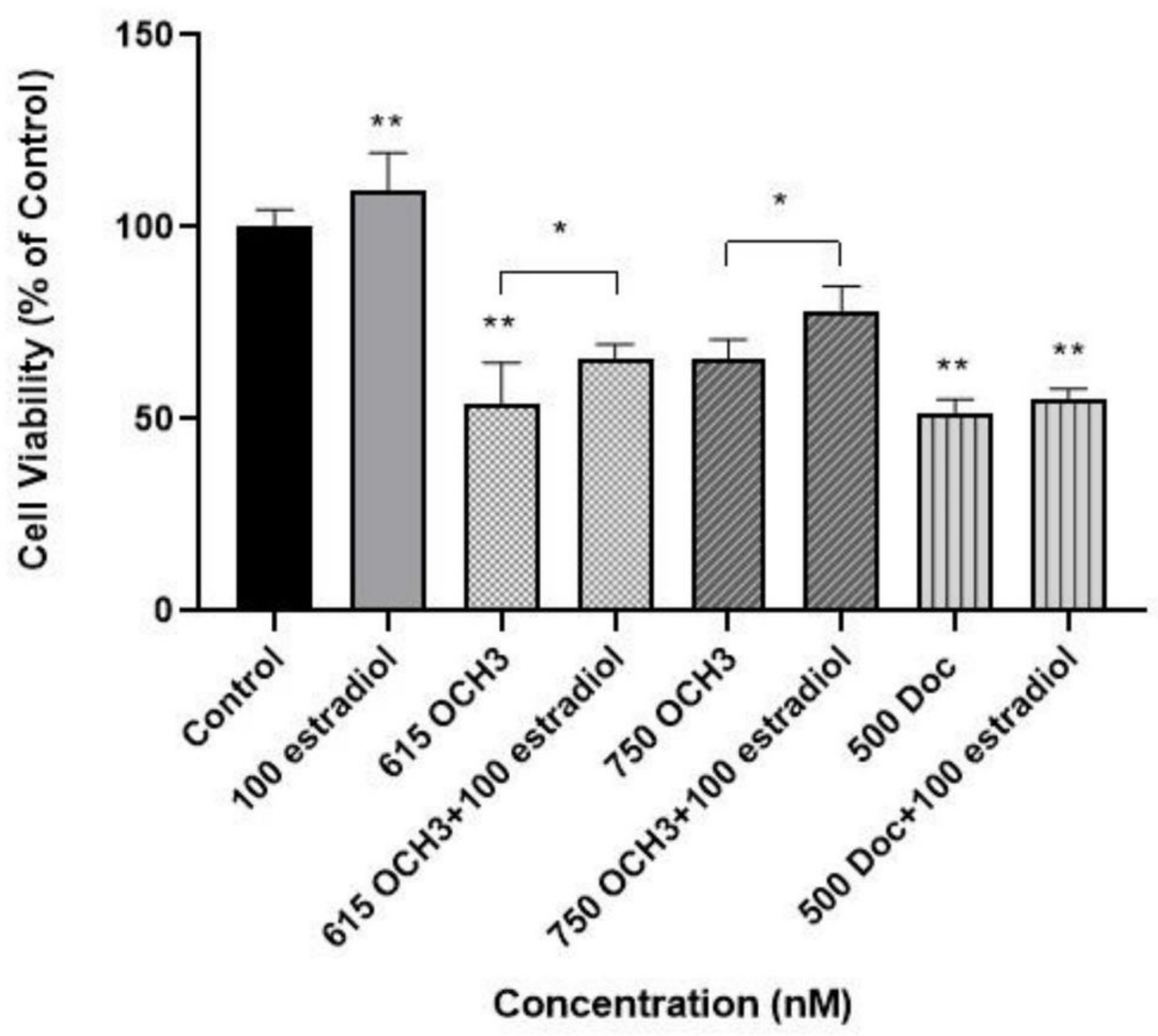

Figure 2

Viability of MCF-7 cells treated with estradiol, $\mathrm{OCH} 3(3 \mathrm{c})$ and Doc alone and in combination for $48 \mathrm{~h}$. Absorbance values were normalized to the control group (Mean $\pm S E, n \geq 3$ ). ${ }^{*} p<0.05,{ }^{*} p<0.01$. 

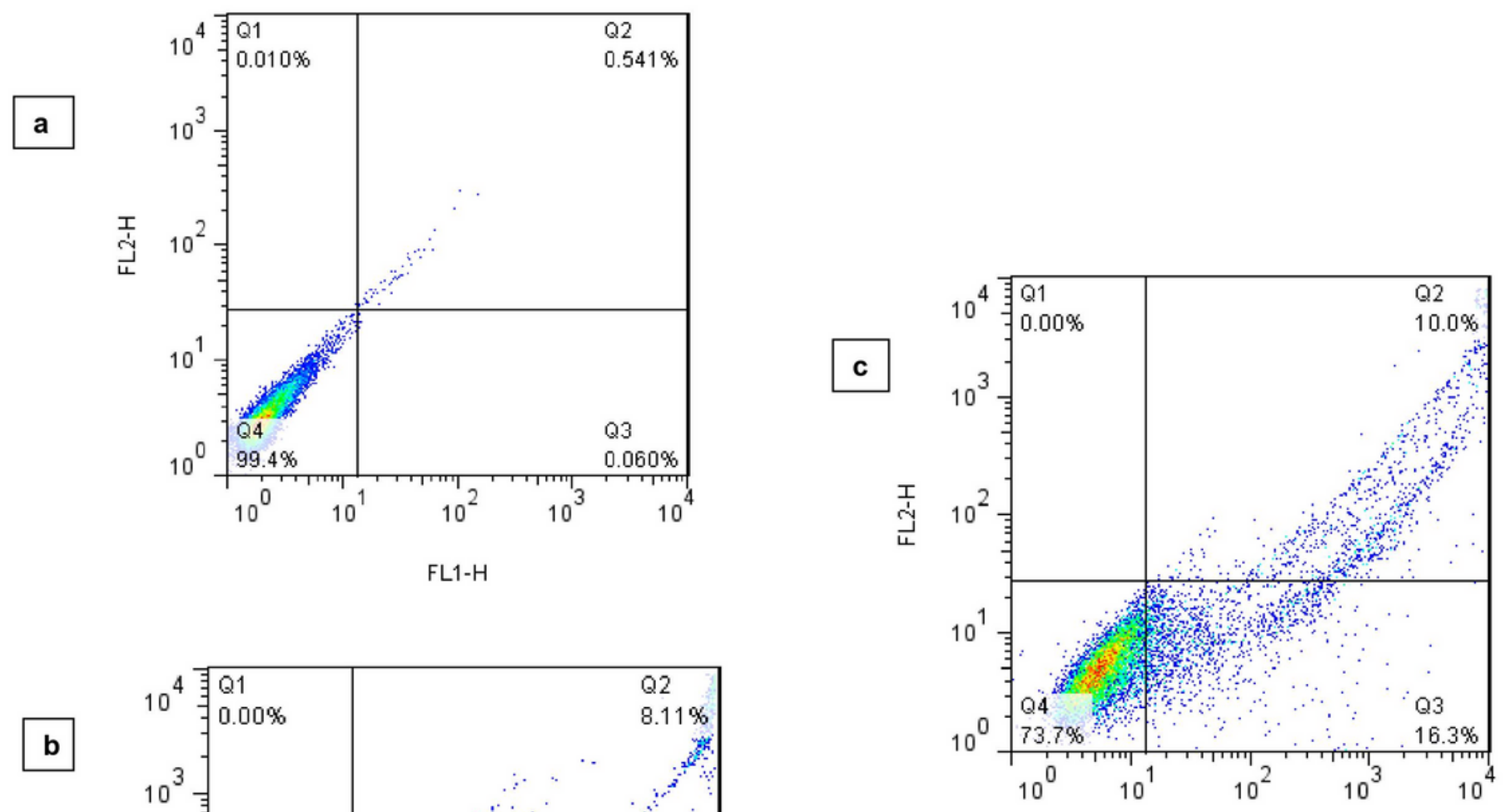

FL1-H

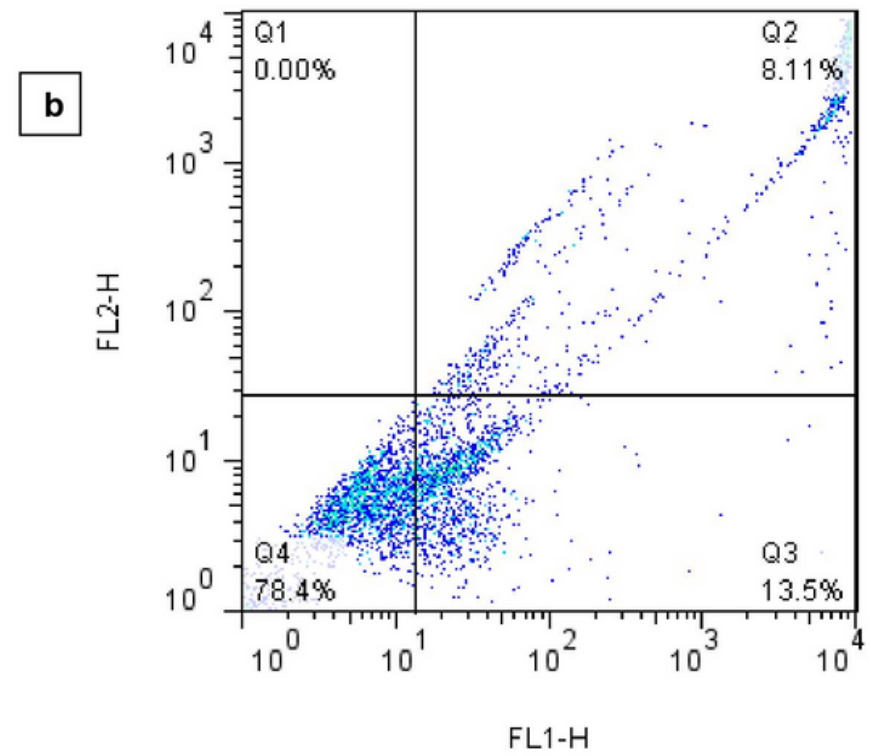

\section{Figure 3}

Flow cytometric analysis of Annexin V-FITC/PI stained Mcf-7 cell line treated with compound 3c. The cells treated with a) DMSO 1\% (negative control); b) IC50 concentration of Doc; C) IC50 concentration of compound 3c. 


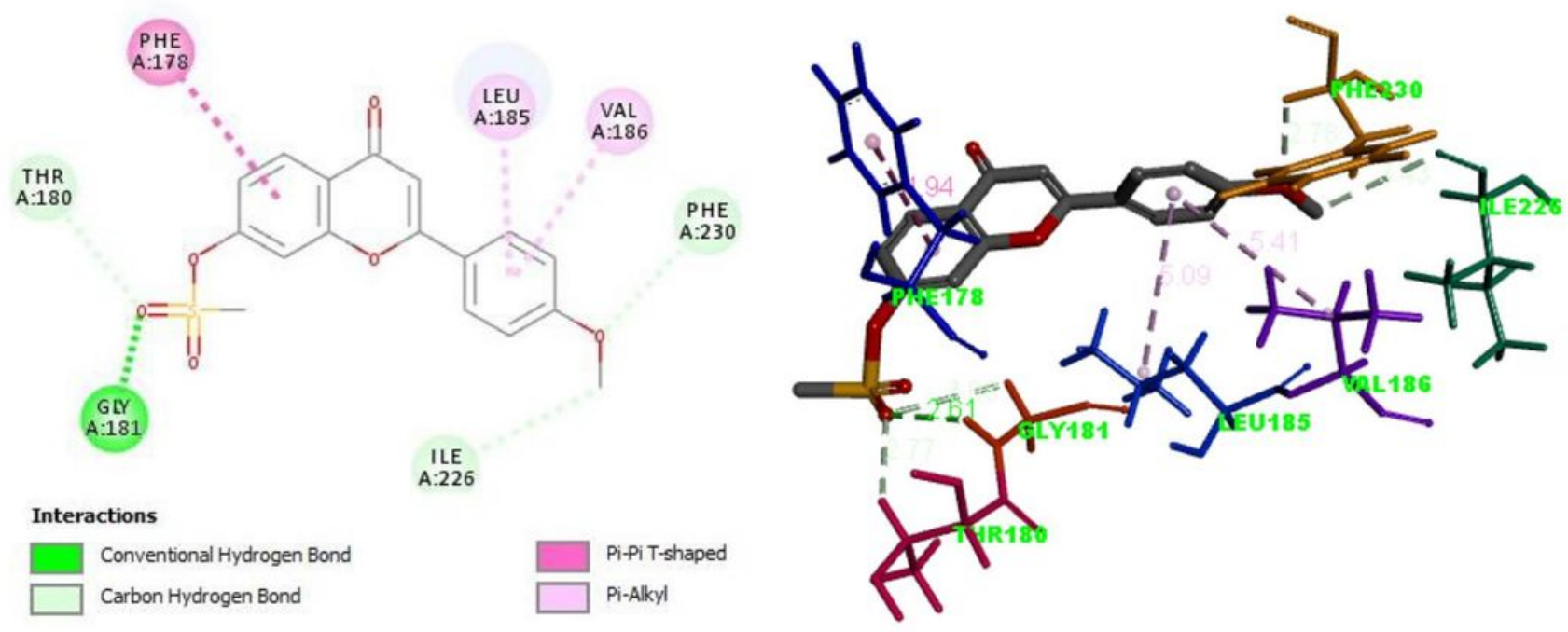

Figure 4

Compound $3 \mathrm{c}$ was docked to the binding pocket of the STS (PDB: 1P49).<smiles>[R9]c1ccc(C(=O)O)c(Br)c1Br</smiles><smiles>[R9]c1ccc(C(=O)Cl)c(Br)c1Br</smiles>

1a-i (ii)<smiles>[R]c1ccc(-c2cc(=O)c3ccc(O)cc3o2)c([R])c1[R]</smiles>

2a-i<smiles>[R3]c1ccc(-c2cc(=O)c3ccc(OS(C)(=O)=O)cc3o2)c([R])c1[R]</smiles>

3a-i

\section{Figure 5}

Scheme 1. Synthesis of 2-phenyl-4-oxo-4H-chromen-7-yl methanesulfonate, Reagents and conditions: (i) Thionyl chloride, Reflux, 2h; (ii) 1: K2CO3, Acetone, Reflux, 8h; 2: H2O and Methanol (1:1), Reflux, 2h; (iii) THF, MSC, Triethylamine, RT, 24h

\section{Supplementary Files}

This is a list of supplementary files associated with this preprint. Click to download.

- GraphicalAbstract2.jpg

- Tables.docx 